\title{
Rapid Response Fault Drilling \\ Past, Present, and Future
}

by Emily E. Brodsky, Kuo-Fong Ma, Jim Mori, Demian M. Saffer,
and the participants of the ICDP/SCEC International Workshop

doi:10.2204/iodp.sd.8.11.2009

\section{Introduction}

New information about large earthquakes can be acquired by drilling into the fault zone quickly following a large seismic event. Specifically, we can learn about the levels of friction and strength of the fault which determine the dynamic rupture, monitor the healing process of the fault, record the stress changes that trigger aftershocks and capture important physical and chemical properties of the fault that control the rupture process. These scientific and associated technical issues were the focus of a three-day workshop on Rapid Response Fault Drilling: Past, Present, and Future, sponsored by the International Continental Scientific Drilling Program (ICDP) and the Southern California Earthquake Center (SCEC). The meeting drew together forty-four scientists representing ten countries in Tokyo, Japan during November 2008. The group discussed the scientific problems and how they could be addressed through rapid response drilling. Focused talks presented previous work on drilling after large earthquakes and in fault zones in general, as well as the state of the art of experimental techniques and measurement strategies. Detailed discussion weighed the tradeoffs between rapid drilling and the ability to satisfy a diverse range of scientific objectives. Plausible drilling sites and scenarios were evaluated. This is a shortened summary of the workshop report that discusses key scientific questions, measurement strategies, and recommendations. This report can provide a starting point for quickly mobilizing a drilling program following future large earthquakes. The full report can be seen at http:// www.pmc.ucsc.edu/ rapid/.

\section{Scientific Motivation}

Scientists have long been asking questions about the physics of earthquakes in the hope that their catastrophic effects can somehow be mitigated. We can now generally delineate the regions where earthquakes are likely to occur. We can use seismic waves to measure the size and determine the location of an earthquake. We can model idealized ruptures and predict the resulting ground motions. We can design buildings that are resistant to the shaking near an earthquake. These advances have had direct benefits for the hundreds of million of people globally who are exposed to earthquake hazards.
However, further progress is largely hampered by a lack of fundamental data about the forces and processes on a fault deep beneath the ground during an earthquake. Knowing how much stress is exerted on the fault during slip is a prerequisite for predicting when the stress will break the fault and how far the fault will slip. We do not know how the fault evolves after an earthquake and how its changing structure resumes the strength required to generate more earthquakes. Even though aftershocks are one of the most predictable consequences of an earthquake, we do not understand the process that causes them. We also struggle to identify what aspects of fault geology separate seismogenic faults from faults that release stress by simply creeping. Immediately after a large earthquake, there is an opportunity to gain crucial information to fill these gaps in knowledge by observing the transient changes related to the rupture. For about two years, the fault is observably changed and a deep borehole can capture measurable signals germane to making progress in earthquake physics. Specifically, a deep borehole can address the following questions:

\section{What Makes an Earthquake Big?}

Earthquakes occur when the increasing local stress exceeds the frictional strength of a fault. A big earthquake occurs when the strength is pervasively low or the stress accumulation is high over a large region of the fault. Strain accumulation is relatively well understood and monitored through geodesy; however, the strength of faults and their time- and slip-dependence are much more poorly measured. At the large displacements and high velocities that characterize big earthquakes, even less is known about frictional strength, which may weaken dramatically during an earthquake. Understanding these currently unconstrained variations in frictional strength and their controlling mechanisms during large earthquakes is key to understanding the faulting process.

\section{How Do Faults Heal for the Next Earthquake?}

In the intervals between earthquakes, fault strength recovers slowly. Much of this process may not be measurable; however, recent work has shown that there is a window of opportunity after an earthquake when observable proxies for fault strength, such as seismic velocity, ground deformation, permeability, and aftershock rate, all change quickly (Brenguier et al., 2008; Kitagawa et al., 2002). Similarly, 
laboratory measurements document fault healing due to rate-and-state frictional and physicochemical processes, both of which evolve rapidly following slip (Hickman et al., 1995; Yasuhara et al., 2005). Scaling of laboratory observations to real faults is problematic but would be greatly aided by direct monitoring of a natural system.

\section{How Do Earthquakes Interact?}

Current data suggest that up to $80 \%$ of earthquakes are generally triggered by another earthquake (Marsan and Lengline, 2008). Some of these aftershocks themselves are large and damaging. However, while aftershocks are the most predictable earthquakes, we do not know if it is the dynamic stress of the seismic waves or the static stress change that activates the new earthquakes. How does stress change result in earthquakes that are delayed by weeks or months after the main shock? Determining the mechanism of triggered events is an important step on the road to earthquake prediction.

\section{What are Important Material and Chemical Properties of the Seismogenic Zone?}

Recent drilling projects on active faults show that fluids, mineralogy, and deformational structures all play important roles in fault behavior (Hickman et al., 1995; Ohtani et al., 2000; Ma et al., 2006). Specific combinations of these material properties may lead faults to episodically slip rapidly as opposed to gradually creep (Dixon and Moore, 2007). By sampling and instrumenting faults, we may be able to determine which combinations of properties lead to large ruptures. Furthermore, during healing following an earthquake, new surface area generated by fracturing is attacked by rapid chemical reactions that can destroy the original record of slip, so the sampling must be done before this process has advanced significantly.

\section{How to Solve the Problems: What to Measure and Why}

In order to learn about friction, healing, interaction, and nucleation, we need measurements of heat, stress, geological structures, frictional properties, permeability, seismic velocity, fluid chemistry, and local ground motion.

\section{Temperature Measurements}

Temperature profiles across the fault are the most direct way to quantify coseismic friction (Lachenbruch and Sass, 1980). Because most of the frictional resistance is dissipated as heat, any temperature increase on the fault at the time of the earthquake is potentially interpretable as a cumulative measure of frictional heat generation during slip. To measure the friction of an earthquake, the temperature must be measured in the vicinity of the seismogenic fault as quickly as possible and at depths where shear stress (a function of the effective normal stress and the effective coefficient of friction) is sufficiently large to generate an observable temperature anomaly (Fig. 1). The possibility of advection of frictionally generated heat by fluid flow following an earthquake must also be considered when interpreting downhole temperature data (Kano et al., 2006). Fulton et al. (2008) used a series of two-dimensional numerical models to simulate transient coupled fluid flow and heat transport to illustrate that temperatures across a fault zone should not be markedly affected by fluid flow driven away from the fault by locally elevated pore pressure (e.g., due to thermal pressurization or shear compaction). The results of these simulations illustrate that although the shape of a frictional heating anomaly will be modified if advective effects are substantial (e.g., in high-permeability cases), it would still be clearly resolvable after two years. Moreover, the use of repeated logging to monitor the evolution of thermal anomalies with time will allow separation of hydrologic (advective) and frictional heating signals.

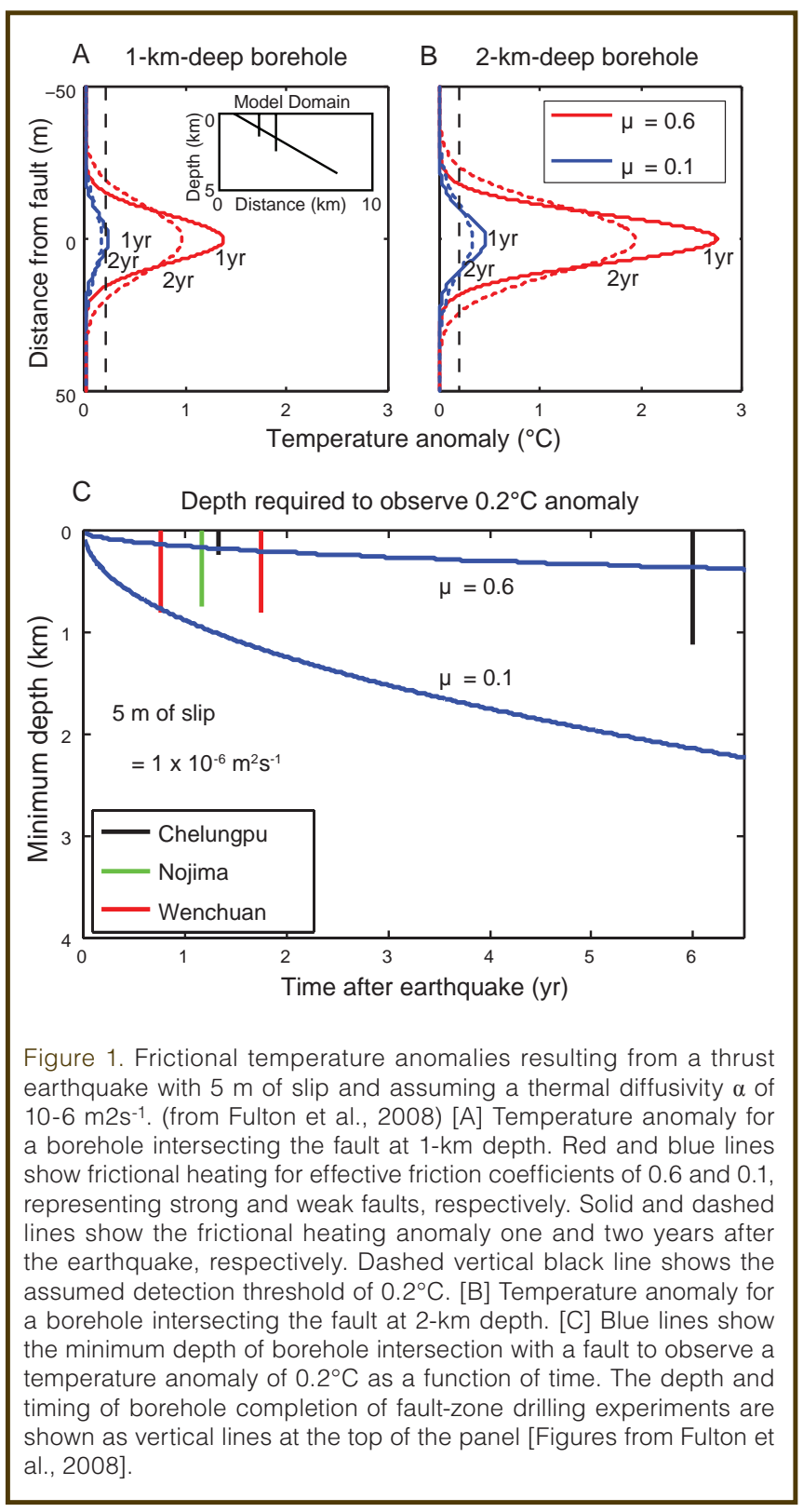




\section{Direct Stress Measurements}

An alternative approach to quantifying fault strength is to measure absolute stress directly. Determining the stress profile during rapid response fault-zone drilling, including the orientations and magnitudes of three-dimensional stresses, may tell us the stress change induced by fault rupture. Although it is difficult to estimate the magnitudes and orientations of three-dimensional stresses, the following quantities provide valuable information: vertical stress by downhole density logging, minimum horizontal stress by extended leak-off test/minifrac/hydraulic fracturing, and maximum horizontal stress by breakout width analyses (Zoback et al., 2003). A good complement to borehole data is core-based anelastic strain recovery (ASR) to produce complementary stress data (Lin et al., 2006). The longer the drilling is delayed, the more the stress will have decayed.

\section{Geology of Cores}

Some of the clearest evidence for the faulting process and frictional dissipation is preserved in fine-scale structures of cores. For instance, the presence of any melt rock (pseudotachylyte) is an immediate indicator of high friction early in the slip process, as heat is required to melt the rocks. Depending on the melt composition and permeability of the host, low friction during slip may be inferred later in the earthquake once melt has lubricated the surface. Geometric structures can also be used to assess the dynamic fluidization of the gouge and any likely rheology (Brodsky et al., 2009). If pseudotachylyte or fluidization structures are found, follow-up laboratory experiments are critical to determining the rheology of the melt or granular flow. Grain-size distribution also contains key information about dissipation. The energy that is absorbed in fracturing and surface creation is energy that is not dissipated by any other means, like friction. Similarly, measurements of fracture density in the boreholeusing borehole imaging tools such as the Formation Micro Imager (FMI) and Resistivity-at-Bit (RAB) — and in the core itself constrain the dissipated energy, including that expended off the primary slip surface. Thus, observing the structure in a core provides some insight into frictional behavior. Fault-zone mineralogy changes rapidly during the healing process emphasizing the need for rapid sampling (Fig.2)

\section{Laboratory Measurements}

Most work on fault friction has been based on laboratory experiments on rocks sliding with limited velocities. However, unusual mineralogy, grain distribution, hydrological conditions, and structure in natural fault zones may significantly complicate the local frictional properties. Laboratory experiments can be manipulated to ascertain the exact effective stress and slip conditions to generate the observed stresses from the available materials. Furthermore, direct measurements of friction in the lab help to assess the applicability of the great body of rock mechanics to actual earthquake fault conditions. To diagnose the relative importance of various physical mechanisms during the earthquake, we must perform laboratory measurements of the frictional properties of gouge from the center of the fault zone (its core), and the results must be compared to the stresses inferred from the temperature and core-based stress measurements. Recent large-velocity experiments on natural gouge removed from fault cores show that significant weakening occurs as slip progresses (Tanikawa and Shimamoto, 2009).

\section{Seismic Velocity}

Seismic velocity has been shown to increase on a fault immediately after an earthquake (Li et al., 1998). A recent noise cross-correlation study showed velocity changes following the 2004 Parkfield earthquake that correlate with the slowly decaying strain transient (Brenguier et al., 2008). However, it is unclear if the seismic velocity change is an entirely shallow phenomenon or if it records a deeper process that is fundamental to the rheology of the fault; thus, measurements in a deep borehole are essential. Because changes often decay as 1 / time, measurements soon after an earthquake are important. Repeated vertical seismic profiles (VSPs) to measure velocity at depth in the nearfield of the fault could capture the progression of fault healing and changes in elastic moduli in the critical time period of the strong aftershock sequence. Borehole measurements should be supplemented with short-term surface deployments of short-period seismometers soon after the earthquake, with repeat deployments.

\section{Hydrogeology}

Dynamic fault-weakening mechanisms rely critically on the transient development of elevated (over ambient) pore fluid pressure via thermal or poro-elastic processes.

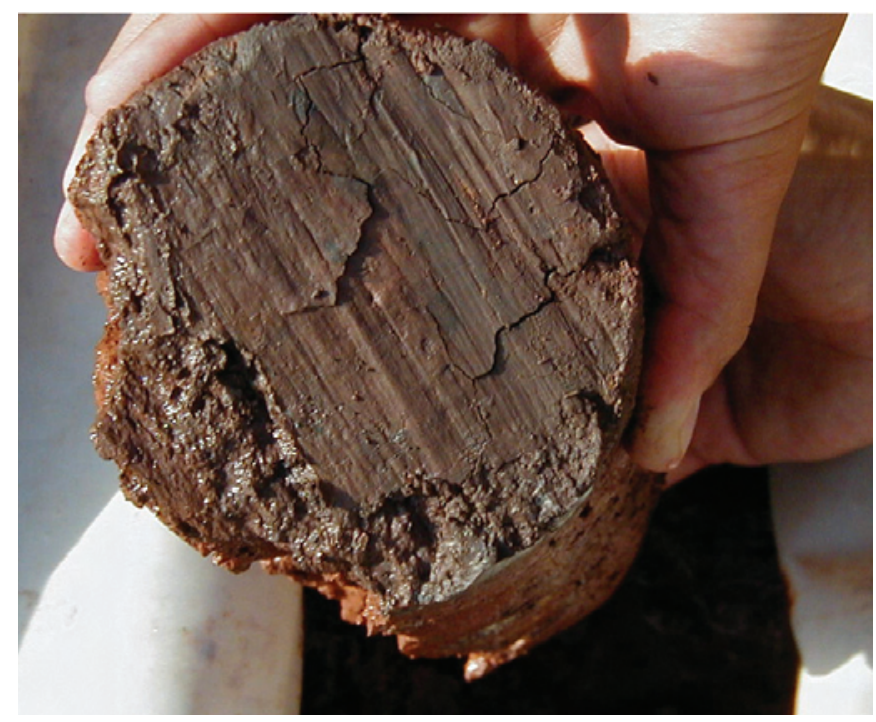

Figure 2. Slip lines observed on the slip surface of the Corinth core. 
Permeability measurements in a fault zone are important in order to assess the sealing potential of the fault. The extent to which fluids may be trapped in a fault zone determines the shear stress during an earthquake and the locking strength before the next event. In addition, permeability can be treated as a proxy for fracturing and damage.

Permeability is known to evolve quickly after an earthquake rupture (Kitagawa et al., 2002). Pore pressure measurements are also important for evaluating static friction, since elevated pore pressure reduces the effective normal stress on faults and their overall shear strength (Rice, 1992). Preliminary interpretations based on drilling observations of the San Andreas Fault Observatory at Depth (SAFOD) (Zoback and Hickman, 2005) and the Chelungpu Fault in Taiwan (Doan et al., 2006) suggest that the fault zone is not overpressured at the depth where it is intersected by the borehole. These observations suggest that long-term weakening from high pore pressure may not be an adequate explanation for the apparent weakness of these fault zones.

\section{Fluid Chemistry}

Chemical precipitates close fractures and generate adhesion; therefore, the fluid chemistry must be sampled to develop a physical-chemical model of the healing process, and should include time series data from the fault core region (highly brecciated zone within the fault) as well as the damage zone. Real-time gas and hydrological monitoring will be critical for ascertaining the in situ chemical conditions.

\section{What has been Learned from Prior Rapid Fault Zone Drilling Projects}

Rapid drilling into a fault zone after an earthquake has already been done in the Nojima Fault, Japan, and the Chelungpu Fault, Taiwan. Future projects will build on this knowledge base. The full report also summarizes results from other fault zone drilling projects (SAFOD, Normal Aigion Fault in the Corinth Rift, Natural Earthquake Laboratory in South African Mines) that are not associated with recent large earthquakes.

\section{Nojima Fault Drilling}

Following the 1995 Kobe, Japan earthquake (Mw 6.9), the first rapid fault-drilling project was carried out on the Nojima Fault, which had surface rupture of about 1-2 m. Seven boreholes to depths of 500-1800 m were completed in fourteen months following the earthquake. Extensive geophysical measurements were made using standard logging techniques, along with borehole televiewer (BHTV), fullbore formation microimager (FMI), and dipole shear sonic imager (DSI) recordings. Resistivity, seismic velocity, and the various imaging techniques were useful for identifying fault zones and other physical properties throughout the drilled section. The borehole logging results were also correlated with the geological features of the core, such as fault gouge and cataclasites (Ikeda, 2001). Temperature measurements with relatively low resolution were made with the standard logging tools, but no signal associated with frictional heating was seen in the vicinity of the fault.

The boreholes provided nearly continuous core samples through the fault zone within granitic rocks and showed its complex geology. Distinct periods of seismic activity were recognized that were accompanied by intense hydrothermal alteration (Ohtani et al., 2000; Boullier et al., 2004; Tanaka et al., 2007). Ultracataclasites and pseudotachylytes that formed at $10-\mathrm{km}$ depth or more were related to previous M6 to M7 earthquakes (Boullier et al., 2001; Murakami and Tagami, 2004). Estimates of the orientation of the local stress field were done with hydrofracturing and stress measurements on cores (Ikeda et al., 2001, Tsukahara et al., 2001; Yamamoto and Yabe, 2001). These stress direction studies showed that the maximum compressive stress was oriented nearly perpendicular to the fault, indicating low values for the static coefficient of friction.

Repeated water-injection experiments are being done in the 1800-m borehole to look for changes in fault permeability. Starting one year after the earthquake, and at subsequent intervals of a few years, water is pumped into the fault zone to induce small earthquakes. The timing and location of induced earthquakes, along with monitoring of resistivity, indicated permeabilities of $10^{-16} \mathrm{~m}^{2}$ to $10^{-14} \mathrm{~m}^{2}$ two years after the earthquake (Tadokoro, 2001). Subsequent injections suggest at least a $50 \%$ decrease in permeability over the subsequent three years (Kitagawa et al., 2002).

\section{Taiwan Chelungpu Fault Drilling Project}

An outstanding feature of the 1999 Chi-Chi, Taiwan earthquake ( $\mathrm{Mw}$ 7.6) was the extensive surface rupture of the Chelungpu fault. The fault break was clearly visible for about $100 \mathrm{~km}$, with surface displacements of 1-12 m. The regions of shallow slip provided the opportunity to access the seismogenic fault with drilling. The Taiwan Chelungpu Fault Drilling Project (TCDP) drilled two boreholes $40 \mathrm{~m}$ apart (completed 65 and 73 months after the earthquake) that penetrated the dipping thrust fault at depths of about one kilometer. The nearby surface fault had a displacement of about $12 \mathrm{~m}$. There were also two shallow boreholes to depths of $330 \mathrm{~m}$ and $180 \mathrm{~m}$ on the northern and southern portions of the fault, respectively, which were completed 18 months after the earthquake (Tanaka et al., 2006).

The TCDP site near the town of Dakeng-where the earthquake had large displacement and slip velocity-was chosen in order to investigate the energy budget and the slip-weakening mechanisms of the earthquake (Ma et al., 2003). Identification of the fault zone in the core samples resulted from combining multiple techniques; they indicated 
a slip zone at $1111 \mathrm{~m}$ in Hole A and $1136 \mathrm{~m}$ in Hole B (Kuo et al., 2005; Ma et al., 2006; Hung et al., 2007; Sone et al., 2007; Yeh et al., 2007; Hirono et al., 2008). Evidence that the black gouge in these regions is in fact the slip surface comes from clay mineralogy, isotropic texture, absence of later reworking microstructures, and a very fine grain size indicative of high fracture energy in the Chi-Chi earthquake's energy budget (Ma et al., 2006).

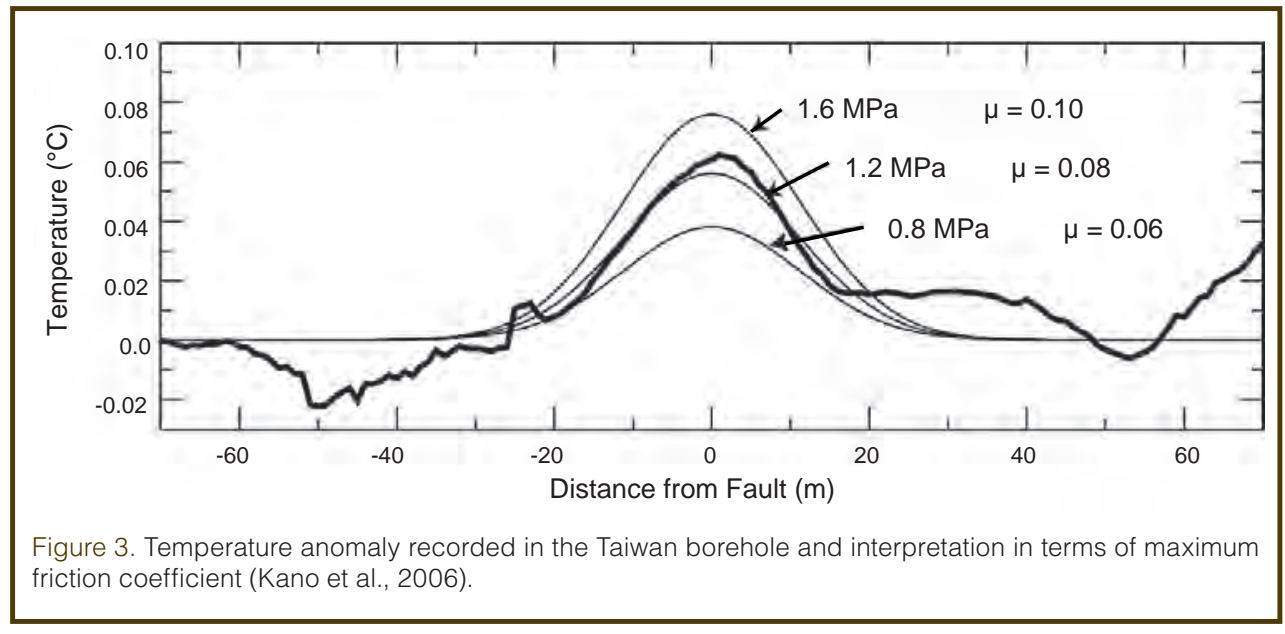

Temperature measurements were made in the shallow and deep boreholes located in the northern region of large slip (Kano et al., 2006; Tanaka et al., 2006). Both studies found a consistent low level of residual heat close to the fault. In terms of frictional levels, these measurements imply a very low apparent coefficient of friction of around 0.1 to 0.2 (Fig. 3). Issues of water flow and determination of thermal diffusivity complicate the interpretation; however, these results show the potential importance of the temperature measurements at depth following a large earthquake.

Physical properties were measured continuously on cores using nondestructive methods (Hirono et al., 2007a). Clayclast aggregates and inverse grain size segregation were found in the Hole A principal slip zone and were interpreted as evidence for gouge fluidization as a result of frictional heating and thermal pressurization (Boutareaud et al., 2008; Boullier et al., 2009). Several other pieces of evidence-such as a magnetic susceptibility anomaly (Hirono et al., 2006; Mishima et al., 2006), clay mineralogy (Kuo et al., 2005; Hashimoto et al., 2008), whole-rock chemistry (Hirono et al., 2007b; Ishikawa et al., 2008), and gouge injections (Otsuki et al., 2005; Boullier et al., 2009) - show that the principal slip zone related to the Chi-Chi earthquake, as well as principal slip zones related to similar past earthquakes, have been heated to as much as $900^{\circ} \mathrm{C}$ and, consequently, are thermally pressurized and fluidized (Hirono et al., 2007b). Fluid circulation seems to be limited in the Chelungpu Fault, but healing processes and aseismic deformation by dissolution-diffusion-deposition mechanisms are important and efficient processes in the fault and damage zones (Boullier et al., 2009).

A cross-hole pumping test indicated a permeability of $10-16 \mathrm{~m}^{2}$ to $10-18 \mathrm{~m}^{2}$ along the fault, and simultaneous monitoring data suggested that the fault zone is moderately overpressured (Doan et al., 2006). Laboratory results on the shallow core samples show that the permeability of the northern region is an order of magnitude less than for the southern region (Tanikawa and Shimamoto, 2009).
TCDP samples have induced high international interest in friction experiments using soft rocks as initial material, and for slip-weakening processes in general. These studies have shown the lateral variability of the principal slip zone structure and thickness, along with the importance of clays and mineralogy of the gouge for slip weakening during coseismic slip. The analyses from FMI and DSI logging also indicate variations of the stress orientation near the principal slip zone, suggesting a complete stress drop during faulting with the exchange of the orientation of the SHmax to SHmin (Wu et al., 2007).

\section{Wenchuan Fault Scientific Drilling Program}

During the workshop, the Wenchuan Fault Scientific Drilling Program began drilling, with the first borehole begun only 178 days after the devastating Mw 7.9 earthquake in Sichuan, China on 12 May 2008. The project plans four deep holes through the faults in the Wenchuan region and represents one the most rapid drilling responses after an earthquake.

\section{Proposed Earthquake Drilling Plan}

Rapid drilling entails rapid decision making. Some of the discussion at the workshop centered on developing a drilling plan that can serve as a blueprint for future rapid response operations. All of the participants were cognizant of the variety of situations likely to be encountered in the real world and understood that no pre-earthquake drilling plan would be appropriate in detail for any particular situation. However, having a scenario plan that specifically addresses the key scientific questions helps provide a useful starting point for the work in the critical time following an earthquake.

Rapid response drilling should be considered whenever there is a large, on-land earthquake with sufficient surface slip (>1 m) to generate large geophysical and geological anomalies at depths accessible to a drilling program. The actual target earthquakes will probably be determined by the local scientific and technical infrastructure. Accessible 
onshore $M \geq 7$ earthquakes with at least $1 \mathrm{~m}$ of surface slip occur about every two to three years. The 1992 Landers, 1999 Izmit, 1999 Hector Mine, and 2002 Denali earthquakes would all have been appropriate targets, in addition to the 1995 Kobe, 1999 Chi-Chi, and 2008 Wenchuan earthquakes. Workshop participants reported on likely scenarios in China, Iran, Japan, New Zealand, Turkey, and the United States. Several of these countries already have fault zone drilling programs underway that could be accelerated and adapted when a large earthquake occurs.

For the plan, several basic selection requirements for drilling sites are aimed at addressing fundamental questions about earthquake energy budgets and fault zone processes. First, it is desirable to drill where the fault and regional geologic structure are well-known and relatively simple. A single major fault strand rather than multiple active traces will provide data that are more easily interpretable in the context of seismological information. Second, drilling should target a region of high co-seismic slip on the fault, as defined

by seismological inversions and surface deformation data. Slip should be at least $1 \mathrm{~m}$ in order to ensure a measurable frictional signal. Ideally, the drilling would reach nucleation depths, although this is unlikely to be feasible in many cases, and thus most drilling projects will concentrate on the problems of friction, healing, and earthquake interaction. Third, crystalline rock is preferred over sedimentary rock because of its low permeability and its well-defined frictional properties. Unconsolidated sediments are particularly problematic for studying the seismogenic zone. Fourth, a dipping fault is ideal (though not required) because it would allow crossing the fault at a high angle with a vertical borehole. This scenario drilling plan assumes a dipping fault. Finally, it would be desirable to drill in a location where there are numerous pre-existing seismological and GPS stations, to provide additional needed information about the earthquake.

A significant challenge in designing and implementing a drilling plan is coordination of multiple downhole measurements and instrument install-
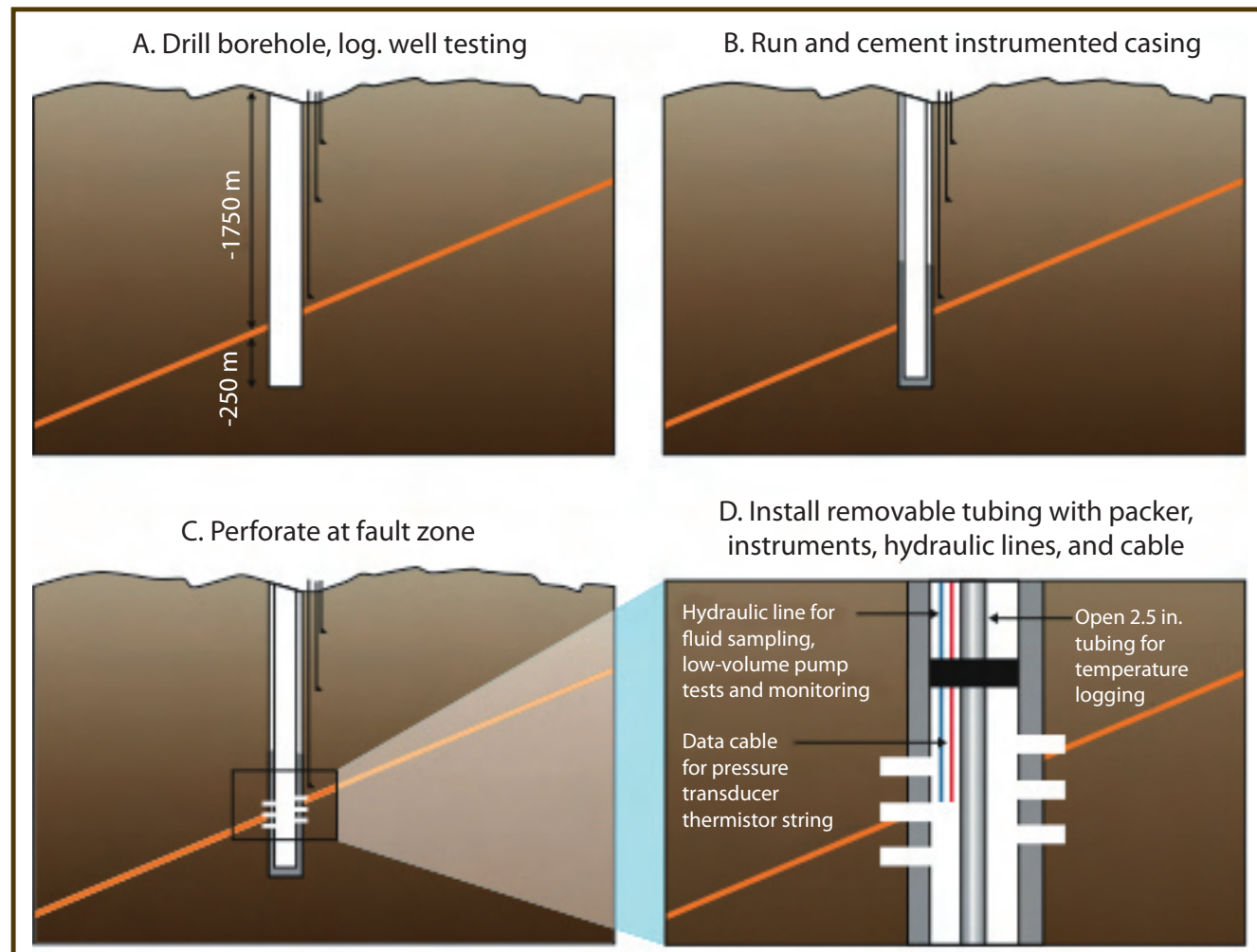

D. Install removable tubing with packer, instruments, hydraulic lines, and cable

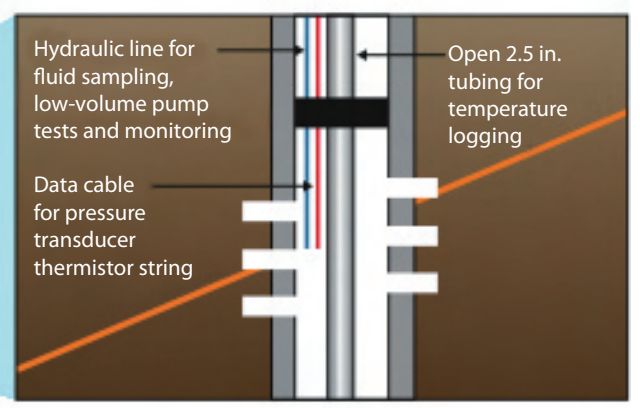

E. Conduct low-volume pump test

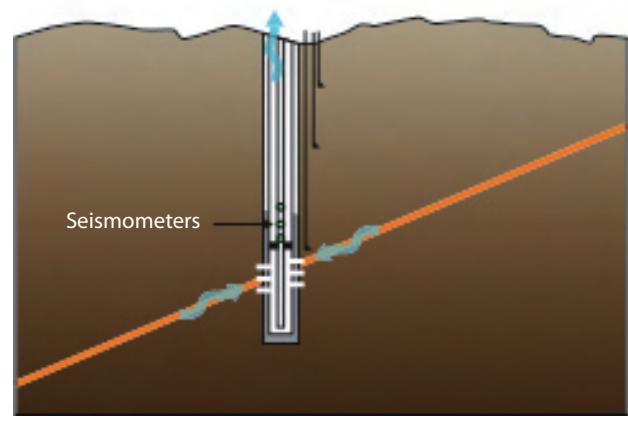

Figure 4. Schematic of a rapid drilling plan. ations, due to competition for limited space in the hole and potential interference. Multiple objectives must be spatially and temporally balanced, requiring care in the following: (a) design and completion strategy, including planning of measurement sequences to minimize interference; and (b) prioritization and compromise of some measurements (e.g., running only low volume perturbation tests for stress and hydrologic measurement objectives, or conducting only limited coring). Key observations of temperature logging, seismometers and strainmeters, hydrologic testing, and fluid sampling, all have specific hole configuration and/or timing requirements that are often conflicting.

We provide a sample drilling plan (Fig. 4) to illustrate how to balance competing measurements in a realistic scenario. One key consideration is the minimum target depth required to obtain meaningful information about frictional heating, given instrument 
resolution and the magnitude of the expected thermal anomaly (based on average shear stress and the total amount of slip). There is a tradeoff between these considerations and the amount of time needed for drilling. For a suite of conservative assumptions about heat generation, a 2 - $\mathrm{km}$-deep hole drilled within six to twelve months following an earthquake is sufficient; deeper drilling is better, but the time and cost increase exponentially with increased depth. This depth range is also adequate for the desired geophysical measurements. This scenario drilling plan shows a $2-\mathrm{km}$-deep hole, penetrating a fault at $1750-\mathrm{m}$ vertical depth. This plan and general completion strategy could be adjusted for any target fault depth, although the details of casing set points and sizes would need to be modified.

\section{Recommendations}

The key recommendation of the workshop is that rapid drilling should be a priority of the international drilling community following on-land earthquakes that occur with more than $1 \mathrm{~m}$ of slip in regions with sufficient infrastructure to support the technical operations. The optimal drill site is on crystalline rock with a dipping fault and well-characterized geology. The hole should be initiated within six months after the earthquake and should be drilled to a depth of at least $2 \mathrm{~km}$.

To achieve this goal, the workshop participants recommend the following courses of action for ICDP and the scientific community (listed separately).

\section{Recommendations for ICDP}

- ICDP should form a standing committee on fault drilling.

- A mechanism should be created to facilitate rapid evaluation and funding of scientific drilling proposals immediately following an earthquake.

- Fault zone drilling projects should include a contingency plan for accelerating or reconfiguring the project in case of a major earthquake.

- An inventory of baseline data on and near major faults should be constructed under the supervision of the standing committee as soon as possible for reference information before an earthquake occurs. The inventory should include existing, accessible boreholes, current seismological and geodetic instrumentation, and paleoseismic constraints. As part of this process, geophysical logging should be conducted on extant boreholes in strategic locations near major faults.

- An emergency response kit should be built and maintained by ICDP, including material stockpiles and borehole instrumentation and including special downhole tools.

- Investments should be made into developing and improving sensors for deep, hot adverse fault zone environments.

\section{Recommendations for the Scientific Community}

- National and regional groups should form and work on scenario plans for their localities. Clear and accurate geological and geophysical information prior to a major earthquake are critical for optimally selecting a study site after the earthquake.

- Complementary seismological and geological studies at potential sites of large earthquakes should be undertaken. Existing boreholes should be logged. These baseline data are critical to post-earthquake interpretations.

\section{Acknowledgements}

The Rapid Response Fault Drilling Workshop and accompanying report were supported by the International Continental Scientific Drilling Program, Southern California Earthquake Center, University of California - Santa Cruz, and Kyoto University.

\section{References}

Boullier, A.M., Fujimoto, K., Ito, H., Ohtani, T., Keulen, N., Fabbri, O., Amitrano, D., Dubois, M., and Pezard, P., 2004. Structural evolution of the Nojima fault (Awaji Island, Japan) revisited from the GSJ drill hole at Hirabayashi. Earth, Planets Space, 56(12):1233-1240.

Boullier, A.M., Ohtani, T., Fujimoto, K., Ito, H., and Dubois, M., 2001. Fluid inclusions in pseudotachylytes from the Nojima fault, Japan. J. Geophys. Res. Solid Earth, 106(B10):21965-21977, doi:10.1029/2000JB000043.

Boullier, A.M., Yeh, E.-C., Boutareaud, S., Song, S.-R., and Tsai, C.-H., 2009. Microscale anatomy of the 1999 Chi-Chi earthquake fault zone. Geochem. Geophys. Geosyst., 10:Q03016, doi:10.1029/2008GC002252.

Boutareaud, S., Boullier, A.M., Beck, P., Calugaru, D.-G., Han, R., and Tsutsumi, A., 2008. Clast-clay aggregates as new indicator of shallow crustal seismic slips. Geophys. Res. Abstr., 10:1607-7962/gra/EGU2008-A-04694.

Brenguier, F., Campillo, M., Hadziioannou, C., Shapiro, N.M., Nadeau, R.M., and Larose, E., 2008. Postseismic relaxation along the San Andreas Fault at Parkfield from continuous seismological observations. Science, 321:1478-1481, doi:10.1126/ science.1160943.

Brodsky, E.E., Rowe, C.D., Manighenni, F., and Moore, J.C., 2009. A geological fingerprint of extremely low viscosity fault fluids during an earthquake. J. Geophys. Res., 114:B01303, doi:10.1029/2008JB005633.

Dixon, T.H., and Moore, J.C., 2007. The Seismogenic Zone of Subduction Thrust Faults. Irvington, N.Y. (Columbia University Press), $680 \mathrm{pp}$.

Doan, M.-L., Brodsky, E.E., Kano, Y., and Ma, K.-F., 2006. In situ measurement of the hydraulic diffusivity of the active Chelungpu Fault, Taiwan. Geophys. Res. Lett., 33:L16317, doi:10.1029/2006GL026889. 
Fulton, P.M., Saffer, D.M., and Brodsky, E.E., 2008. The role of advection on fault zone temperature after an earthquake: implications for rapid response drilling. EOS Trans. AGU, Fall Meeting Suppl., 89(52), Abstract T53F-05.

Hashimoto, Y., Tadai, O., Tanimizu, M., Tanikawa, W., Hirono, T., Lin, W., Mishima, T., Sakaguchi, M., Soh, W., Song, S.-R., Aoike, K., Ishikawa, T., Murayama, M., Fujimoto, K., Fukuchi, T., Ikehara, M., Ito, H., Kikuta, H., Kinoshita, M., Masuda, K., Matsubara,T., Matsubayashi, O., Mizoguchi, M., Nakamura, N., Otsuki, K., Shimamoto, T., Sone, H., and Takahashi, M., 2008. Characteristics of chlorites in seismogenic fault zones: The Taiwan Chelungpu Fault Drilling Project (TCDP) core sample. $e$-Earth, 3:1-6, http://www.electronic-earth.net/3/issue1.html.

Hickman, S., Sibson, R., and Bruhn, R., 1995. Introduction to special section: Mechanical involvement of fluids in faulting. $J$. Geophys. Res., 100:12831-12840, doi:10.1029/95JB01121.

Hirono, T., Lin, W., Yeh, E.-C., Soh, W., Hashimoto, Y., Sone, H., Matsubayashi, O., Aoike, K., Ito, H., Kinoshita, M., Murayama, M., Song, S.-R., Ma, K.-F., Hung, J.H., Wang, C.-Y., and Tsai, Y.-B., 2006. High magnetic susceptibility of fault gouge within Taiwan Chelungpu fault: nondestructive continuous measurements of physical and chemical properties in fault rocks recovered from Hole B, TCDP. Geophys. Res. Lett., 33:L15303, doi:10.1029/2006GL026133.

Hirono, T., Sakaguchi, M., Otsuki, K., Sone, H., Fujimoto, K., Mishima, T., Lin, W., Tanikawa, W., Tanimizu, M., Soh, W., Yeh, E.-C., and Song, S.-R., 2008. Characterization of slip zone associated with the 1999 Taiwan Chi-Chi earthquake: X-ray CT image analyses and microstructural observations of the Taiwan Chelungpu fault. Tectonophysics, 449:63-84, doi: 10.1016/j.tecto.2007.12.002.

Hirono, T., Yeh, E.-C., Lin, W., Sone, H., Mishima, T., Soh, W., Hashimoto, Y., Matsubayashi, O., Aoike, K., Ito, H., Kinoshita, M., Murayama, M., Song, S.-R., Ma, K.-F., Hung, J.-H., Wang, C.-Y., Tsai, Y.-B., Kondo, T., Nishimura, M., Moriya, S., Tanaka, T., Fujiki, T., Maeda, L., Muraki, H., Kuramoto, T., Sugiyama, K., and Sugawara, T., 2007a. Nondestructive continuous physical property measurements of core samples recovered from hole B, Taiwan ChelungpuFault Drilling Project. J. Geophys. Res., 112:B07404, doi:10.1029/2006JB004738.

Hirono, T., Yokoyama, T., Hamada, Y., Tanikawa, W., Mishima, T., Ikehara, M., Famin, V., Tanimizu, M., Lin, M., Soh, W., and Song, S.-R., 2007b. A chemical kinetic approach to estimate dynamic shear stress during the 1999 Taiwan Chi-Chi earthquake. Geophys. Res. Lett., 34:L19308, doi:10.1029/ $2007 \mathrm{GL} 030743$.

Hung, J.-H., Wu, Y.-H., Yeh, E.-C., Wu, J.-C., and TCDP Scientific Party, 2007. Subsurface structure, physical properties, and fault zone characteristics in the scientific drill holes of Taiwan Chelungpu-fault Drilling Project. Terr. Atmos. Ocean. Sci., 18(2):271-293, doi:10.3319/TAO.2007.18. 2.271(TCDP).

Ikeda, R., 2001. Outline of the fault zone drilling project by NIED in the vicinity of the 1995 Hyogo-ken Nanbu earthquake, Japan. Island Arc, 10:199-205, doi:10.1046/j.1440- 1738.2001.00318.x.

Ikeda, R., Iio, Y., and Omura, K., 2001. In situ stress measurements in NIED boreholes in and around the fault zone near the 1995 Hyogo-ken Nanbu earthquake, Japan. Island Arc, 10:252260, doi:10.1046/j.1440-1738.2001.00323.x.

Ishikawa, T., Tanimizu, M., Nagaishi, K., Matsuoka, J., Tadai, O., Sakaguchi, M., Hirono, T., Mishima, M., Tanikawa, W., Lin, W., Kikuta, H., Soh, W., and Song, S.-R., 2008. Coseismic fluid-rock interactions at high temperatures in the Chelungpu fault. Nature Geosci., 1:679-683, doi:10.1038/ ngeo308.

Kano, Y., Mori, J., Fujio, R., Ito, H., Yanagidani, T., Nakao, S., and Ma, K.-F., 2006. Heat signature on the Chelungpu fault associated with the 1999 Chi-Chi, Taiwan earthquake. Geophys. Res. Lett., 33:L14306, doi:10.1029/2006GL026733.

Kitagawa, Y., Fujimori, K., and Koizumi, N., 2002. Temporal change in permeability of the rock estimated from repeated water injection experiments near the Nojima fault in Awaji Island, Japan. Geophys. Res. Lett., 29:1483, doi:10.1029/ 2001GL014030.

Kuo, L.-W., Song, S.-R., and Chen, H.-Y., 2005. Characteristics of clay mineralogy in the fault zone of the TCDP and its implication. EOS Trans. AGU, Fall Meet. Suppl., 86(52), Abstract T43D-05.

Lachenbruch, A.H., and Sass, J.H., 1980. Heat flow and energetics of the San Andreas fault zone. J. Geophys. Res., 85:6185-6222.

Li, Y.-G., Vidale, J.E., Aki, K., Xu, F., and Burdette, T., 1998. Evidence of shallow fault zone strengthening after the 1992 M7.5 Landers, California, earthquake.Science,279(5348):217-219, doi:10.1126/science.279.5348.217.

Lin, W., Kwasniewski, M., Imamura, T., and Matsuki, K., 2006. Determination of three-dimensional in situ stresses from anelastic strain recovery measurement of cores at great depth. Tectonophysics, 426:221-238, doi: 10.1016/j. tecto.2006.02.019.

Ma, K.-F., Brodsky, E.E., Mori, J., Ji, C., Song, T.-R.A., and Kanamori, H., 2003. Evidence for fault lubrication during the $1999 \mathrm{Chi}-$ Chi, Taiwan, earthquake (Mw7.6). Geophys. Res. Lett., 30(5):1244, doi:10.1029/2002GL015380.

Ma, K.-F., Tanaka, H., Song, S.-R., Wang, C.-Y., Hung, J.-H., Tsai, Y.-B., Mori, J., Song, Y.-F., Yeh, E.-C., Soh, W., Sone, H., Kuo, L.-W., and Wu, H.-Y., 2006. Slip zone and energetics of a large earthquake from the Taiwan Chelungpu-fault Drilling Project. Nature, 444:473-476, doi:10.1038/nature05253.

Marsan, D., and Lengline, I., 2008. Extending earthquakes' reach through cascading. Science, 319:1076-1079, doi:10.1126/ science.1148783.

Mishima, T., Hirono, T., Soh, W., Ikehara, M., Lin, W., Tanikawa, W., Yeh, E.-C., Song, S.-R., and Wang, C., 2006. Thermal history estimation of the Taiwan Chelungpu Fault using rock-magnetic methods. Geophys. Res. Lett., 33:L23311, doi:10.1029/2006GL028088.

Murakami, M., and Tagami, T., 2004. Dating pseudotachylyte of the Nojima fault using the zircon fission-track method. Geophys. Res. Lett., 31:L12604, doi:10.1029/2004GL020211.

Ohtani, T., Fujimoto, K., Ito, H., Tanaka, H., Tomida, N., and Higuchi, T., 2000. Fault rocks and past to recent fluid characteristics 
from the borehole survey of the Nojima fault ruptured in the 1995 Kobe earthquake, southwest Japan. J. Geophys. Res., 105(B7):16161-16171, doi:10.1029/2000JB900086.

Otsuki, K., Uduki, T., Monzawa, N., and Tanaka, H., 2005. Clayey injection veins and pseudotachylyte from two boreholes penetrating the Chelungpu Fault, Taiwan: their implications for the contrastive seismic slip behaviors during the 1999 Chi-Chi earthquake. Island Arc, 14:22-36.

Rice, J.R., 1992. Fault stress states, pore pressure distributions, and the weakness of the San Andreas Fault. In: Evans, B., and Wong, T.-F., (Eds.), Fault Mechanics and Transport Properties of Rocks. San Diego, Calif., (Academic Press), 475-503.

Sone, H., Yeh, E.-C., Nakaya, T., Hung, J.-H., Ma, K.-F., Wang, C.-Y., Song, S.-R., and Shimamoto, T., 2007. Mesoscopic structural observations of cores from the Chelungpu fault system, Taiwan Chelungpu-Fault Drilling Project hole-A, Taiwan. Terr. Atmos. Ocean.Sci., 18(2):359-377, doi:10.3319/ TAO.2007.18.2.359(TCDP).

Tadokoro, K., 2001. Repeated water injection experiments at the Nojima fault zone, Japan: induced earthquakes and temporal change in permeability. Poster presentation. ICDP Workshop on Drilling the Chelungpu Fault. Investigating the Physics of Faulting for a Recent Large Earthquake, 27 -30 September 2001, Taiwan, Taipei.

Tanaka, H., Chen, W.-M., Wang, C.-Y., Ma, K.-F., Urata, N., Mori, J., and Anod, M., 2006. Frictional heat from faulting of the 1999 Chi-Chi, Taiwan, earthquake. Geophys. Res. Lett., 33:L16316, doi:10.1029/2006GL026673.

Tanaka, H., Omura, K., Matsuda, T., Ikeda, R., Kobayashi, K., Murakami, M., and Shimada, K., 2007. Architectural evolution of the Nojima fault and identification of the activated slip layer by Kobe earthquake. J. Geophys. Res., 112:B07304, doi:10.1029/2005JB003977.

Tanikawa, W., and Shimamoto, T., 2009. Frictional and transport properties of the Chelungpu fault from shallow borehole data and their correlation with seismic behavior during the 1999 Chi-Chi earthquake. J. Geophys. Res., 114:B01402, doi:10.1029/2008JB005750.

Tsukahara, H., Ikeda, R., and Yamamoto, K., 2001. In situ stress measurements in a borehole close to the Nojima Fault. Island Arc, 10:261-265, doi:10.1046/j.1440-1738.2001.00324.x.

Wu, H.-Y., Ma, K.-F., Zoback, M., Boness, N., Ito, H., Hung, J.-H., and Hickman, S., 2007. Stress orientations of Taiwan ChelungpuFault Drilling Project (TCDP) hole-A as observed from geophysical logs. Geophys. Res. Lett., 34:L01303, doi:10.1029/2006GL028050.

Yamamoto, K. and Yabe, Y., 2001. Stresses at sites close to the Nojima Fault measured from core samples. Island Arc, 10:266-281, doi:10.1046/j.1440-1738.2001.00325.x.

Yasuhara, H., Marone, C., and Elsworth, D., 2005. Fault zone restrengthening and frictional healing: the role of pressure solution. J. Geophys. Res., 110:B06310, doi:10.1029/ 2004JB0033272005.

Yeh, E.-C., Sone, H., Nakaya, T., Ian, K.-H., Song, S.-R., Hung, J.-H., Lin, W., Hirono, T., Wang, C.-Y., Ma, K.-F., Soh, W., and Kinoshita, M., 2007. Core description and characteristics of fault zones from Hole-A of the Taiwan Chelungpu-Fault
Drilling Project. Terr. Atmos. Ocean. Sci., 18(2):327-357, doi:10.3319/TAO.2007.18.2.327(TCDP).

Zoback, M.D. and Hickman, S.H., 2005. Preliminary observations of stress and fluid pressure in and near the San Andreas Fault at depth in the SAFOD boreholes. EOS Trans. AGU, Fall Meet. Suppl., 86(52), Abstract T21A-0438.

Zoback, M.D., Barton, C.A., Brudy, M., Castillo, D.A., Finkbeiner, T., Grollimund, B.R., Moos, D.B., Peska, P., Ward, C.D., and Wiprut, D.J., 2003. Determination of stress orientation and magnitude in deep wells. Int. J. Rock Mech. Min. Sci., 40:1049-1076, doi:10.1016/j.ijrmms.2003.07.001.

\section{Authors}

Emily E. Brodsky, Deptartment of Earth and Planetary Sciences, UC Santa Cruz, 1156 High Street, Santa Cruz, Calif., 95060, U.S.A., e-mail: brodsky@pmc.ucsc.edu.

Kuo-Fong Ma, Department of Earth Sciences, Institute of Geophysics National Central University, No.300, Jhongda Road, Jhongli City, Taoyuan County 32001, Taiwan (R.O.C.). Jim Mori, Disaster Prevention Research Institute, Kyoto University, Gokasho, Uji, Kyoto, 611-0011, Japan.

Demian M. Saffer, Department of Geosciences, The Pennsylvania State University, 310 Deike Building, University Park, Pa., 16802, U.S.A.

and participants of the ICDP/SCEC International Workshop on Rapid Response Fault Drilling 